\title{
Paciente Oncológica Portadora de Ileostomia: Abordagem da Assistência de Enfermagem
}

\author{
Veríssimo, Francisco Arlysson da Silva; Lima, Liene Ribeiro de; Melo, Wesley \\ Soares de; Chaves, Anne Fayma Lopes; Calderon, Carolina Jimenez; Holanda, \\ Rose-Eloíse; Ferreira, Paulo Jorge de O. \\ Faculdade Católica Rainha do Sertão — arlysson.ver@hotmail.com
}

Introdução: a mulher quando acometida por câncer já carrega em si o sofrimento e uma série de reações negativas desencadeadas na maioria dos casos, sendo potencializado esse pesar quando vindo acompanhado com outras patologias. o câncer de ovário e a confecção de uma estomia íleo-intestinal provocam na mulher alterações não somente no sistema biológico, mas também afeta emocional e fisicamente o indivíduo, chegando a prejudicar sua relação social e provocando diversas mudanças em sua perspectiva de vida. Esses eventos estressores, exigem do indivíduo respostas de enfrentamento que causam impacto em sua saúde, gerando significativas alterações no seu estilo de vida. Objetivo: Descrever as ações de enfermagem frente a uma paciente oncológica portadora de ileostomia. Metodologia: a pesquisa trata-se de um estudo de caso realizado com uma paciente oncológica portadora de ileostomia, internada em um Hospital de Médio Porte de referência para a região do Cariri, situada no município de Barbalha/CE, a 577 quilômetros da capital Fortaleza, Sul do Ceará, Brasil. Os dados foram colhidos através de informações advindas do prontuário, bem como do relato de familiares. Estes foram analisados e feito julgamento clínico usando as taxonomias estabelecidas pela North American Nursing Diagnosis Association e Classification of Nursing Interventions. Foram levados em consideração para o estudo os aspectos da autonomia, não-maleficência, beneficência e justiça, bem como obedecido as recomendações da Resolução 196/96 do Conselho Nacional de Saúde/ Ministério da Saúde. Resultados: Os principais diagnósticos de enfermagem encontrados foram: Distúrbio na imagem corporal; Ansiedade; Risco de prejuízo para integridade da pele; Potencial para alteração da nutrição. As principais intervenções implementadas, foram: Encorajar a paciente a verbalizar sentimentos; Estimular a paciente a realizar as atividades de autocuidado; Conversar sobre os progressos do paciente e enfatizar quando sua condição melhorar ou se estabilizar; Conduzir uma avaliação completa da paciente, numa abordagem multidimensional. Conclusão: Conclui-se que o enfermeiro, quando atua com ações integrais e humanizadas no exercício profissional, pode adaptar o cliente/paciente a um dado acontecimento, proporcionando-o melhoras no enfrentamento. Vale salientar que neste processo é considerado os aspectos pessoais, emocionais, culturais e experiências singulares deste indivíduo, para que assim favoreça seu processo de saúde a fim de manter um bom estado físico, psicológico e social.

Veríssimo, Francisco Arlysson da Silva; Lima, Liene Ribeiro de; Melo, Wesley Soares de; Chaves, Anne Fayma Lopes; Calderon, Carolina Jimenez; Holanda, Rose-Eloíse; Ferreira, Paulo Jorge de O.. Paciente Oncológica Portadora de Ileostomia: Abordagem da Assistência de Enfermagem. In: Anais do Congresso Internacional de Humanidades \& Humanização em Saúde [= Blucher Medical Proceedings, num.2, vol.1]. São Paulo: Editora Blucher, 2014. ISSN 2357-7282

DOI 10.5151/medpro-cihhs-10649 